Received: 06/07/2018

\title{
A Model and Questionnaire of Language Education Glocalization in Iran
}

\section{Esmaeel Ali Salimi}

Dr., Faculty of Persian Literature and Foreign Languages, Allameh Tabataba'i University, Tehran, Iran, easalimi@atu.ac.ir

\section{Mohammad Meisam Safarzadeh}

$\mathrm{PhD}$ Candidate of Persian Literature and Foreign Languages, Allameh Tabataba'i University, Tehran, Iran, mm.safarzadeh@atu.ac.ir

The study aimed at developing a hypothesized model and a validated questionnaire of language education glocalization (LEG) for the first time to accomplish systematic data generation and collection of the Iranian EFL teachers' perceptions regarding the LEG. In order to develop the model, extensive readings of the related literature were executed and expert consultation was conducted leading to formation of a hypothesized model. To test the model a questionnaire was developed and validated to tap the components of the model. Cronbach's Alpha coefficient was used to measure the reliability of the questionnaire estimating 0.96 for the whole questionnaire and exploratory factor analysis along with content analysis confirmed the validity of the questionnaire. After running exploratory factor analysis, to check whether the questionnaire data fits the hypothesized model of LEG introduced at the beginning of the study, a confirmatory factor analysis was done. Then, the final version of the questionnaire was administered to 270 language teachers to gather the data to feed it to the model to see the extent to which the model fit the data. The results of the study revealed that although the model has been the first one of its kind, it displayed a reasonable degree of reliability and validity.

Keywords: glocalization, language education, teacher perception, questionnaire, validity, reliability

\section{INTRODUCTION}

Globalization and movement to a more interconnected international community have been supported by great technological changes, such as advances in digital communication, permitting the continuous transfer of large amounts of data worldwide and advances in transportation, facilitating the fast, cost-effective traveling of people and carrying of goods over long distances. "Globalization" has caused levels of

Citation: Salimi, E. A., \& Safarzadeh, M. M. (2019). A Model and Questionnaire of Language Education Glocalization in Iran. International Journal of Instruction, 12(1), 1639-1652. https://doi.org/10.29333/iji.2019.121104a 
interaction among people from different national, cultural, religious, and ethnic backgrounds, incomparable to the past. While successful communication has long been an important characteristic of any effective social interaction among people from different cultures, within the recent years, it has become vital.

Together with the process of globalization, English as the international language of choice, or lingua franca, has established itself as the world's common language for academic as well as business interaction (Bamgbose, 2001; Graddol, 1997, 2006; Murata \& Jenkins, 2009; Seidlhofer, 2001, 2004, 2009). Recently, the phenomenon of English taking the role of a lingua franca (ELF) has led to a shift in paradigm wherein the prominence of English spoken by native speakers as the standard has been reconsidered resulting in the continuing acceptance of local English varieties (Murata \& Jenkins, 2009). This new revolutionary perspective empowered non-native speakers of English to become ELF speakers rather than mere learners (Mauranen, 2007). In this view, localized uses of the English language are no longer viewed as deficiencies or errors but, considered to be exclusive varieties of their own rights. The lack of sensitivity for language use in local context is the side effect of overemphasizing the global situation. Due to the importance of the target contextual factors determined by political, economic and cultural differences, the introduction of a foreign language which is suitable to the target contexts seems crucial (Bax 2003; Holliday 1994; Sung 2010). According to Bax (2003) "Context should be the very first thing to be taken into account before any methodological or language system decisions are taken. ... Language teaching anywhere will be benefit from full attention to the context in which it operates". (p. 284)

Undoubtedly, the growth of ELF phenomenon enjoys robust implications for the foreign or second language English users. For instance, inability in producing native-like accents is no longer felt inferior by non-native speakers. Now, they can use English more flexibly and in any way they feel at ease with using it in order to achieve their communicative objective. Thus, the usage of English as an international language is being enriched by users all around the world leading to the expansion of the varieties of English beyond the traditional forms of English (British and/or American).

Despite the positive wave generated by this new phenomenon, yet a general consensus needs to be reached on the ideal route of this evolution to global English. Reviewing the literature discloses that there exist a number of practical considerations; among them is the existence of a tendency among many teachers, learners, and users of English toward a need for a standard English (Modiano, 2001; Seidlhofer, 2001, 2004; Trudgill \& Hannah, 2002).

Anyway, to decide upon what to teach students and how to assess their performance, English teachers need to have a common frame of reference without which they face difficulty. This role was traditionally played by British and American English.

Another difficulty to be considered is the problem of integration of local varieties of English into the curriculum of English teaching and learning. The sociologist Roland Robertson (1995) introduced the concept of 'glocalization', which shares some common 
grounds with the phenomenon of ELF. He defines glocalization as "the simultaneity-the co-presence-of both universalizing and particularizing tendencies" (p. 25). Differentiating between globalization and localization Swales (2004), defined the notion of glocalization as "a bifurcation away from the historically powerful nation state in two directions: one upward towards a world increasingly dominated by multinational corporations and international and supranational entities... and one downward (as it were) towards regional aspirations, niche marketing, local involvements" (p. 11).

In a nutshell, both ELF and glocalization believe in combining global ideas with local requirements. As for the other countries around the world, these two phenomena (ELF and glocalization) have a number of implications for English language education in Iran.

In order to know how glocalization is perceived by Iranian EFL teachers, this study, will survey Iranian EFL teachers' perspectives on glocalized language teaching. This study suggests that knowing about Iranian EFL teachers' perceptions of glocalization in language education may provide us with good insights into the most appropriate ways to design teacher education programs for the context of Iran and help Iranian EFL teachers find their real role wherein they can contribute to English education in Iran.

Despite the strength of qualitative approaches, conducted studies in anthropology, sociology and psychology, if reviewed, one can find a larger number of studies that have employed quantitative approaches. Along with recent studies in the above mentioned disciplines, language education research has been affected by and endorsed due to this tendency towards quantitative research. Despite the fruitfulness of the qualitative approaches such as interviewing, diary studies, and ethnography, these research methods face some shortcomings. To overcome these shortcomings, developing a framework or model seems very advantageous. In many different countries and contexts some very successful models including language, culture and identity models have been developed and used. Based on the just mentioned arguments, the present study, as a three-phase research, has sought for three major goals. Primarily, the study aimed at developing a hypothesized model of language glocalization in Iran. To test the model, as the second phase of the study, a questionnaire was developed and validated. At phase three, the developed questionnaire was used to gather the data to feed it to the model to see the extent to which the model fit the data.

\section{Glocalization of language education}

The concept of glocalization initially emerged to describe the adaption of multinational goods or service companies to specific local cultural settings to expand globally as part of these companies' global expansion policies (Robertson, 1995). McDonald's, Starbucks, KFC, and Wendy's as distinguished global food companies that have adapted their menus based on local tastes are instances of glocalization in the business. The notion of glocalization, later, penetrated into other fields.

Regarding the glocalization of (English) language education, as identified in different parts of the world, it should be considered that the purpose of localization is not merely for international communication but for intranational interactions. For instance, to meet their intercultural and intracultural communication needs, native Australians developed 
English varieties considering both global and local norms (Sharifian, 2010). As a matter of fact, while Australians employed global norms to interact with people from other countries, they used local norms to communicate with people from different tribes of their own country. As a further example, glocalization of English can be observed in Singapore, wherein various first languages are spoken. This phenomenon, as argued by Alsagoff (2010), has happened in spite of all the attempts made by the government to establish the roles of the Singaporians' first languages/mother tongues and that of English as a global language respectively for intranational and international communications. He also added, drawing a borderline between these two language types has been demonstrated to be impossible; as a matter of fact, the mixture of two cultures and languages has led to a continuum of glocal-local English, in which degrees of variation are displayed, rather than considering a dichotomy of the standard or nonstandard English.

Moreover, according to Shi (2013), in China, as another example of using localized varieties of English, several glocalized Englishes are used including Chinese Pidgin English, Chinglish, Chinese English, and China English listed from the farthest to the closest Standard English in terms of the acceptability of English. Li (1993) classified the Chinese Pidgin English and Chinglish as the least acceptable or "bad English," and Chinese English as fairly acceptable or "beginners' English".

The extension of the glocalization dialogue in the research and the pedagogy of English as a foreign language (EFL) can be of great help in giving further insights into English teaching and learning in Iran in terms of global-local needs considerations. For this purpose, a two-phase study was planned. For the first phase, at the present study, a model and a questionnaire were developed.

\section{METHOD}

In applied linguistics, teachers' perceptions are achieved through several methodological tools among which are questionnaires, interviews and ethnographic observations. Though interview and ethnography are two beneficial research tools, their administration and scoring are generally costly and time-consuming. In the use of interviewing and ethnographic observations inherently there exist practical problems, a possible solution of which can be validated questionnaires.

Some studies have taken advantage of questionnaires as a way of collecting the attitudinal data. They have mostly used open-ended questionnaires, yet with insufficient information regarding their indexes of validation and reliability. Moreover, a number of researches have remained the devoted supporters of merely qualitative methodologies to FL/SL education study and have avoided mixed-methods or quantitative studies. Nowadays, since FL/SL education studies are full of intricate constructs being rendered into quantifiable measures, more mixed-methods or quantitative research tools can be great help for presenting the educational perceptions of the teachers. More elaborately, close disciplines such as anthropology, psychology and sociology were pioneers in mixing both qualitative and quantitative methods for achieving teachers' perceptions about FL/SL education concerns. 


\section{Research Design}

The present study aims at exploring the Iranian teachers' perceptions on the glocalization of language education. Nevertheless, no validated questionnaire has been developed for teachers' perceptions of LEG in Iranian context. Hence, the researchers went through scientific phases of questionnaire development to provide a reliable and validated LEG questionnaire through which Iranian teachers' perceptions are explored for the first time in this study and it can be of great help as a beneficial tool for the future studies alike.

\section{Filling the gap: a LEG questionnaire}

To do many large-scale surveys in the field of applied linguistics, developing a reliable and valid questionnaire can be of great help. However, to do so, the contextual variations should be taken into account. Therefore, LEG construct and its various components can be defined with regard to cultural, sociological, linguistic and identityrelated considerations. Hence, the researchers made an attempt to develop a questionnaire encompassing the relevant components of glocalized language education for Iranian context. To achieve the goal, a number of considerable steps were taken and iterative processes undergone. To establish the theoretical framework of the study the first step was reviewing the previous works and relevant theories.

Having reviewed the related literature, a number of components encapsulating LEG were identified. A team of experts on applied linguistics was consulted to confirm the components' accuracy and appropriateness. Collecting further views and comments from the experts, the components were respecified and reconfigured with some required changes applied. Having reviewed the literature on LEG, five main components including Varieties of English, Glocal Needs, Native/Standard English, Culture and Identity, and L2/FL Model were drafted out. The Varieties of English component can show the belief that there exist varieties of English rather than mere American or British English. The component of Glocal Needs measures the belief to the fact that theorizers, policy makers, material developers and practitioners should purposefully channelize language education to meet local and global needs simultaneously. The next component, i.e., Native/Standard English, explores the belief to the fact that language teaching should reflect what skilled L2/FL users do, not only native speakers. Culture and Identity as the fourth component shows the belief to the fact that in current intercultural communication age, people no longer seek to become a native-like English user, rather they proudly claim their local identity and culture. Finally, the fifth component aims at exploring the belief to the fact that English no more belongs to American or British native speakers, but whoever uses it is liable to fine tune it for his/her communicational needs. Table 1 below shows the definition for each of the identified components of LEG. 
Table 1

The LEG questionnaire components and definitions

\begin{tabular}{lll}
\hline \multicolumn{1}{c}{ Component } & Definition \\
\hline English & & $\begin{array}{l}\text { The belief to the fact that there is no more only American or British } \\
\text { English. There are varieties of English (e.g. Nigerian, Indian, or } \\
\text { African English) with their independent growth and increasingly } \\
\text { distinctive characters. }\end{array}$ \\
\hline 2. & Glocal Needs & $\begin{array}{l}\text { The belief to the fact that through Glocalization, language } \\
\text { education should be channelized purposefully to meet local and } \\
\text { global needs simultaneously. }\end{array}$ \\
\hline 3. & Native/Standard & $\begin{array}{l}\text { The belief to the fact that insofar as language teaching reflects what } \\
\text { native speakers, not skilled L2/FL users, do, it has only an indirect } \\
\text { link to the L2/FL user target. }\end{array}$ \\
\hline 4. & Culture and & $\begin{array}{l}\text { The belief to the fact that people, in current intercultural } \\
\text { communication age, seek no more to become a native like English } \\
\text { user, but they proudly claim for their local identity and culture. }\end{array}$ \\
\hline 5. & L2/FL Model & $\begin{array}{l}\text { The belief to the fact that English no more belongs to American or } \\
\text { British native speakers. It belongs to whoever uses it. So its users } \\
\text { should appropriate it to meet their communication needs. }\end{array}$ \\
\hline
\end{tabular}

\section{Instrument development and validation}

As the review of the related literature showed that there exists no questionnaire to explore teachers' perceptions on LEG, the researchers decided to develop a questionnaire serving the objectives of the study. According to Dornyei (2010) "developing a questionnaire is a stepwise process, and the quality of the final instrument depends on the cumulative quality of each sub-process" (p.111). Therefore, the whole phases of the questionnaire development process and its validation were done following the Dornyei's (2010) and Brown's (2001) questionnaire development manuals.

\section{Respondents}

The study was done between June 2016 and October 2016, and the respondents were Iranian English teachers with different language teaching experiences, ages, genders and educational backgrounds. The number of the questionnaire respondents for the initial piloting were 40,110 for the reliability-checking phase, 180 for the exploratory factory analysis, and finally 270 for the confirmatory factor analysis.

\section{Questionnaire development}

To accomplish systematic data generation and collection of the teachers' perceptions regarding the glocalization of language education, the LEG questionnaire was designed. The reliance of the questionnaire was on the self-reported values of the teachers. The questionnaire involved three subdivisions: personal information, items in the form of 35 statements about LEG, and the teachers' opinions wherein teachers were asked to elaborate on their views on five statements, each one representing one of the questionnaire components. The article only focuses on the data generated from the second section of the questionnaire. Teachers were asked to report about their values 
and indicate the extent to which they agree or disagree with any of the given values regarding glocalized language education. The response categories were: completely disagree, disagree, slightly disagree, slightly agree, agree, and completely agree.

This article pays particular attention to the questionnaire as a research tool. To formulate the LEG questionnaire items conceptual and empirical insights from the related literature were utilized as operationalization processes. Furthermore, an attempt was made by the researchers to include purposefully in the survey those items which were capable of eliciting teachers' perceptions and views about the under-study subject, i.e. LEG. Hence, in the first place, the models and frameworks of LEG upon which the construction of the items of the questionnaire were founded is described. Then, the findings from the analysis of the questionnaire data are presented with reference to the research question, i.e., how teachers value different aspects of LEG. Afterward, the results from factor analysis carried out in order to identify underlying dimensions of LEG are reported. Subsequently, these factors are applied in a cluster analysis to generate profiles of LEG reported values as the characterization of differences among teachers. Finally, the implications of our findings for policy and practice are taken into consideration.

\section{Constructing items}

The reviewing of the related literature is the initial step for any instrument development. This step is taken with the aim of (1) searching if there are any existing instruments and if there are any characteristics they possess, and (2) establishing a good theoretical framework for the instrument to be constructed. Thus, the study already met these two goals to develop the desired model. Therefore, on the basis of the hypothesized model, a pool of items was generated. To do so, content sampling as well as multi-item scales were applied. In this step, several items were generated because they could better measure or tap the target domain under investigation and also because the researchers already knew some items would be eliminated in the pilot study stage. In generating the items, the researchers made an endeavor to make easy-to-grasp items employing a natural language to avoid any difficulty and ambiguity. Moreover, an attempt was made to keep questions away from being double-barreled: a single item asking two or more questions. The researchers also tried not letting the questionnaire get too long. Finally, the overlapping items were removed and the similar ones were merged.

\section{Adopting and adapting the rating scale}

The current study utilized Likert as the most popular and widely-used rating scale. The six options employed by the researchers included completely agree, agree, slightly agree, slightly disagree, disagree and completely disagree. It should be noted that a five-option rating scale was initially opted by the researchers including: completely agree, agree, no idea, disagree and completely disagree. Yet, as respondents are generally conservative in their responses and might merely choose 'no idea' in some apparently delicate items, a six-option scale was used for two reasons: to avoid the respondents' hedge and to make the data normally distributed. As such, respondents were required to show the degree of their agreement or disagreement to each item on a 
six-point Likert rating scale. To score the items, the options were received scores from 6 (completely agree) to 1 (completely disagree) at the two ends of the six-option scale.

\section{Designing the personal information section}

The gender, education level, and years of language teaching experience were the personal information that were sought in this section of the questionnaire. Once generated, to check and revise, the items were given to a panel of six experts to check their accuracy as well as intelligibility. The panel of experts was professionals in applied linguistics. They were consulted in deciding upon the presence or absence of each item resulting in the reduction of the number of items from 60 to 35 . The 25 discarded items were omitted due to a number of mentioned reasons by the panel such as the ambiguity, inappropriateness, redundancy and lengthiness of the items. The criteria for the acceptance or omission of an item from the questionnaire was the experts' consensus of ideas.

\section{Piloting and analyzing items}

Before piloting the questionnaire, some further points were taken into consideration. Initially, an attempt was made to keep the questionnaire as short as possible, yet, this is done to the extent that the central points are eliminated. To achieve this goal, the researchers did their best to construct the questionnaire in a way that its completion take at most 20 minutes. The fulfillment of this goal makes the respondents more willing to contribute and guarantees their full cooperation. To make respondents feel secure in answering the items, the questionnaire did not require respondents to disclose their names. During the questionnaire administration, its title, i.e. language education glocalization questionnaire was removed to avoid participants' responses being affected by it.

All the above points being considered, the initial piloting of the questionnaire was done. For the initial pilot study, the questionnaire was administered to a sample of 40 teachers from the target population. At this phase of the study, the rough copies of the questionnaire were given to the participants by hand. Some of the items were modified as a consequence of using the helpful results of the piloting phase.

\section{Measuring the reliability indexes}

Cronbach's Alpha coefficient was used to measure the questionnaire internal consistency. According to Dornyei (2010), an acceptable measure for the reliability index of a questionnaire should be above 0.60 . Hence, the study chose 0.60 as the acceptable reliability index and below that as the weak index. The questionnaire contained 35 items administered to 110 Iranian English language teachers. The Cronbach's Alpha results indicated the internal consistency of 0.96 for the whole questionnaire, and $0.89,0.92,0.88,0.89$, and 0.87 respectively for the five components of LEG as the subscales in the questionnaire (Table 2). 
Table 2

Components reliability indexes

\begin{tabular}{lll}
\hline Component & \multicolumn{1}{c}{ Items } & Reliability \\
\hline 1 & $22,35,31,10,2,18,13,15,23$ & 0.89 \\
\hline 2 & $29,24,33,9,30,16,32$ & 0.92 \\
\hline 3 & $26,27,28,25,20,21,12$ & 0.88 \\
\hline 4 & $7,8,4,3,11,17$ & 0.89 \\
\hline 5 & $1,14,5,6,19,34$ & 0.87 \\
\hline
\end{tabular}

Validating the questionnaire

Following Alderson and Banerjee (1996) as well as Converse and Presser (1986), the questionnaire validation process was done. Thus, face validity, content validity and construct validity were investigated. To fulfill face validity, the researchers did their best to design a questionnaire enjoying a good layout, standard font type and size, reasonable lengthiness, etc. Then, to establish the questionnaire content validity, the study's team of consultant experts was asked to judge to what extent each of the items truly represented the objective of the LEG questionnaire. The experts also were asked to reflect on the wording of the items and the instructions given in the questionnaire. Furthermore, by means of think-aloud technique, six English language teachers from the target population were given the questionnaire to respond. Based on the acquired information, the researchers implemented some modifications leading to rewording in some items. It should be noted the face and content validity were done prior to estimating the reliability indexes. Once all these steps were taken, 35 items were finalized forming five components within LEG questionnaire.

To explore the construct validity, a two-stage process was employed. Initially, the congruency of the questionnaire with the LEG theories in the literature was checked. Then, in two separate administrations, exploratory as well as confirmatory factor analyses were run with the purpose of checking the validity statistically. Before running factor analysis, a number of criterions must be met. Assessing the data suitability for factor analysis is the first step. To do so, two criterions should be met: "sample size and the strength of association among the variables (or items)" (Pallant 2007, p. 180). Concerning the sample size, among the researchers there stand different outlooks, upon which the most agreed one is the larger, the better. The criterion of five to ten respondents for each item was selected for the current study. This criterion was met by 180 participants taking part in the phase of the exploratory factor analysis.

The internal consistency of the questionnaire items was the second criterion to be checked for the suitability of the data before running factor analysis. This criterion can be determined by the Sphericity Test of Bartlett and the test of Kaiser-Meyer-Olkin (KMO). To indicate data factorability, the Sphericity Test of Bartlett ought to be significant, i.e. $\mathrm{p}<0.05$ and the index of KMO ranging from 0 to 1 should be 0.6 or above, or else the appropriateness of the data for running factor analysis goes under question. Table 3 shows the results of Bartlett's test and KMO measure for the present study to be 0.84 for KMO and $\mathrm{P}=0.00$ for Bartlett's test of sphericity as significant. 
Considering these two values it can be assumed that some significant factors are there to be extracted from the data.

Table 3

KMO and Bartlett's test results

\begin{tabular}{ll}
\multicolumn{1}{c}{ KMO and Bartlett's } \\
\hline KMO Measure of Sampling Adequacy & .840 \\
\hline Bartlett's test of sphericity Approximately chi-square & 7233.702 \\
\hline df & 595 \\
\hline Sig. & .000 \\
\hline
\end{tabular}

\section{Exploratory factor analysis}

The criterions for the data factorability being met, the researchers ran factor analysis employing Principle Components Analysis (PCA) method. To decide upon the number of factors to be extracted, the Kaiser's criterion, reading that the eigenvalues equal to 1.0 and above to be acceptable, was used. The five factors accounted for $70.67 \%$ of the total variance (generally any variance over $60 \%$ is acceptable). The five factors allocated separately $15.52 \%, 14.60 \%, 14.35 \%, 13.58 \%$, and $12.59 \%$ of the total variance to themselves.

All the items showed variable communalities greater than 0.30 . The questionnaire communality values ranged from 0.62 to 0.84 . All the factor correlations were at acceptable levels for the questionnaire. Table 4 displaying factor analysis results run based on PCA, shows the five factors and their degree of loadings. The factor loadings were checked by the researchers to see if there exists any item not being highly loaded to be eliminated from the questionnaire. Fortunately, all the questionnaire items showed an acceptable level of loadedness under the five factors.

\section{Confirmatory factor analysis}

After running exploratory factor analysis to check whether the questionnaire data fits the hypothesized model of LEG introduced at the beginning of the study, a confirmatory factor analysis was done. At this phase, the final version of the questionnaire was administered to 270 language teachers. The questionnaire was designed on eSurveyCreator (www.esurveycreator.com) and sent to the participants of the study through their emails to fill out the questionnaire online. 
Table 4

Factor loading based on PCA

\begin{tabular}{|c|c|c|c|c|c|}
\hline \multicolumn{6}{|c|}{ Components $^{\mathrm{a}}$} \\
\hline & 1 & 2 & 3 & 4 & 5 \\
\hline 22 & .694 & & & & \\
\hline 35 & .692 & & & & \\
\hline 31 & .680 & & & & \\
\hline 10 & .650 & & & & \\
\hline 2 & .604 & & & & \\
\hline 18 & .592 & & & & \\
\hline 13 & .531 & & & & \\
\hline 15 & .509 & & & & \\
\hline 23 & .489 & & & & \\
\hline 29 & & .759 & & & \\
\hline 24 & & .743 & & & \\
\hline 33 & & .740 & & & \\
\hline 9 & & .684 & & & \\
\hline 30 & & .647 & & & \\
\hline 16 & & .638 & & & \\
\hline 32 & & .608 & & & \\
\hline 26 & & & .772 & & \\
\hline 27 & & & .755 & & \\
\hline 28 & & & .752 & & \\
\hline 25 & & & .711 & & \\
\hline 20 & & & .572 & & \\
\hline 21 & & & .531 & & \\
\hline 12 & & & .529 & & \\
\hline 7 & & & & .832 & \\
\hline 8 & & & & .743 & \\
\hline 4 & & & & .737 & \\
\hline 3 & & & & .661 & \\
\hline 11 & & & & .469 & \\
\hline 17 & & & & .455 & \\
\hline 1 & & & & & .722 \\
\hline 14 & & & & & .703 \\
\hline 5 & & & & & .688 \\
\hline 6 & & & & & .624 \\
\hline 19 & & & & & .581 \\
\hline 34 & & 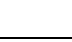 & 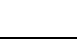 & & .479 \\
\hline
\end{tabular}

\section{DISCUSSION AND CONCLUSION}

This study aims to find out the level of students achievement when using multimedia The need for glocalized language education requires different and additional professional development in language teachers and teacher educators' practices preparing them for their new tasks. Therefore, glocalized language education, as an 
educational innovation, needs to gain more attention from EFL teachers and teacher educators.

The educational change and innovations in teacher education should not proceed without considering current teacher knowledge and teachers' established teaching practices (Connelly \& Clandinin, 1988; Xu \& Connelly, 2009). Then, the study was done to investigate Iranian EFL teachers' perceptions of glocalized language education.

The main goal of this study was to develop a model and a validated questionnaire for the first time through which Iranian EFL teachers' perceptions being explored as a beneficial tool for the further similar studies. Hence, a model was initially hypothesized and later a questionnaire was developed. More elaborately, the researchers went through scientific phases to generate a reliable and validated LEG questionnaire.

The results of the study revealed that although the model has been the first one of its kind, it displayed a reasonable degree of reliability and validity as confirmed by the statistical procedures. The developed and validated model and the questionnaire of this study can have many practical applications for Iranian EFL teachers as well as future researches in other contexts. In other words, the developed questionnaire carries certain benefits over other data collection tools for LEG research. In fact, among the main advantages of generating such a questionnaire are data collection ease and speed as well as providing objective scores. In addition, easy extrapolation of the data is another merit. To complement the deficiencies of the questionnaires' data collection, it is suggested that in research studies any questionnaire be accompanied by other data collection tools, e.g. interviews.

Furthermore, researchers from other contexts can also follow the steps in current study in developing and validating similar models and questionnaires. However, contextual variances need to be attended to and afterward the questionnaire to be rechecked for the degree of the reliability and validity. Although the reliability and validity of the model and the questionnaire were statistically confirmed, it is recommended that to test the model and probably to add or remove any components and statements to the model and the questionnaire, more rigorous studies be conducted.

The last but not the least, developing such a questionnaire would also be a leap towards quantitative approaches in LEG research where a more perceptible picture of globalized second language education is obtained.

\section{REFERENCES}

Alderson, C. J., \& Banerjee, J. (1996). How Might Impact Study Instruments Be Validated? Unpublished manuscript commissioned by UCLES.

Alsagoff, L. (2010). Hybridity in ways of speaking: The glocalization of English in Singapore. In L. Lim, A. Pakir, and L. Wee (Eds.), English in Singapore: Modernity and management (pp. 109-130). Hong Kong, China: Hong Kong University Press.

Bamgbose, A. (2001). World Englishes and Globalization. World Englishes, 20, 357363. 
Bax, Stephen. (2003). The End of CLT: A Context Approach to Language Teaching. ELT Journal, 57 (3), 278-287.

Brown, J. D. (2001). Using Surveys in Language Programs. Cambridge: Cambridge University Press.

Connelly, F M., \& Clandinin, D. J. (1988). Teachers as curriculum planners: Narratives of experience. New York: Teachers College Press.

Converse, J. M., \& Presser, S. (1986). Survey Questions: Handcrafting the Standardized Questionnaire. London: Sage.

Dornyei, Z. (2010). Questionnaires in Second Language Research: Construction, Administration, and Processing. 2nd ed. London: Routledge.

Graddol, D. (1997). The future of English. London: The British Council.

Graddol, D. (2006). English next: Why global English may mean the end of "English as a foreign language". London, UK: British Council.

Holliday, Adrian. (1994). The House of TESEP and the Communicative Approach: The Special Needs of State English Language Education. ELT Journal 48 (1), 3-11.

Li, W. (1993). China English and Chinglish. Foreign Language Teaching and Research, 4,18-24.

Mauranen, A. (2007). English as a lingua franca: Speakers not learner. Retrieved from http://www.academia.edu/1858131/

Modiano, M. (2001). Ideology and the ELT practitioner. International Journal of Applied Linguistics, 11, 159-173.

Murata, K., \& Jenkins, J. (2009). Global Englishes in Asian contexts: Current and future debates. Basingstoke, UK: Palgrave Macmillan.

Pallant, J. (2007). SPSS Survival Manual: A Step-by-step Guide to Data Analysis Using SPSS for Windows. 3rd ed. McGraw Hill: Open University Press.

Robertson, R. (1995). Glocalization: Time-space and homogeneity-heterogeneity. In M. Featherstone, S. Lash, \& R. Robertson (Eds.), Global modernities (pp. 25-44). London, UK: Sage.

Seidlhofer, B. (2001). Closing a Conceptual Gap: The Case for a Description of English as a Lingua Franca. International Journal of Applied Linguistics 11, 133-158.

Seidlhofer, B. (2004). Research Perspectives on Teaching English as a Lingua Franca. Annual Review of Applied Linguistics, 24, 209-239.

Seidlhofer, B. (2009). World Englishes and English as a lingua franca: Two frameworks or one? In T. Hoffmann and L. Siebers (Eds.), World Englishes-Problems, properties and prospects. (pp. 376-379). Amsterdam: John Benjamins. 
Sharifian, F. (2010). Glocalization of English in world Englishes: An emerging variety among Persian speakers of English. In M. Saxena \& T. Omoniyi (Eds.), Contending with globalization in world Englishes (pp. 137-158). Bristol, UK: Multilingual Matters.

Shi, X. (2013). The Globalization of English: A Chinese Case Study. Journal of Developing Societies, 29, 89-122.

Sung, K.Y. (2010). Promoting Communicative Language Learning Through Communicative Tasks. Journal of Language Teaching and Research, 1 (5), 704-713.

Swales, J. (2004). Research genres. Cambridge, UK: Cambridge University Press.

Trudgill, P., \& Hannah, J. (2002). International English: A guide to varieties of standard English. London, UK: Arnold.

Xu, S. J. \& Connelly, F. M. (2009). Narrative Inquiry for Teacher Education and Development: Focus on English as a Foreign Language in China. Teaching and Teacher Education, 25(2), 219-227. 